\title{
Hypertension and Angiotensin II Hypersensitivity in Aminopeptidase A-deficient Mice
}

\author{
Takashi Mitsui, ${ }^{1}$ Seiji Nomura, ${ }^{1}$ Mayumi OKada, ${ }^{1}$ Yasumasa Ohno, ${ }^{1}$ Honami Kobayashi, ${ }^{1}$ \\ Yutaka NaKashima, ${ }^{1}$ Yasutaka Murata, ${ }^{1}$ MiKihito TaKeuchi, ${ }^{1}$ NaOhiKo Kuno, ${ }^{1}$ \\ Tetsuo Nagasaka, ${ }^{2}$ JiYang O-WANG, ${ }^{3}$ Max D COOPER, ${ }^{4}$ and ShigehIKo MizUtani ${ }^{1}$
}

Local concentrations of the vasopressor peptide, angiotensin II (Angll), depend upon the balance between synthesis and degradation. Previous studies of blood pressure (BP) regulation have focused primarily on the generation of Angll and its receptors, and less attention has been devoted to angiotensin degradation. Aminopeptidase A (APA, EC 3.4.1 1.7) is responsible for the $\mathrm{N}$-terminal cleavage of Angll, a hydrolytic event that serves as a rate-limiting step in angiotensin degradation. To evaluate the physiological role of APA, we examined BP homeostasis in APA-deficient mice. We measured basal BP and BP with continuous infusion of Angll in APA mutant mice by tail-cuff method. We also evaluated the development and histology of Angll-targeted organs as well as urine excretion in these mice. Homozygous APA mutant mice were found to have elevated basal systolic BP when compared with heterozygous mutant and wild-type littermate mice. Infusion of Angll led to an enhanced systolic BP response in the APA-deficient mice. Despite the sustained elevation of BP in APA knockout mice, neither their renal and cardiac sizes nor their histological appearances were not different from control mice. Moreover, the volume, osmolality, and electrolyte content of the urine were normal in APA-deficient mice. APA deficiency increased baseline BP and enhanced the hypertensive response to increased levels of Angll. These findings indicate a physiological role for APA in lowering BP and offer novel insight into the mechanisms for developing hypertension.

\section{INTRODUCTION}

The role of the renin-angiotensin system (RAS) in the maintenance of blood pressure (BP) has been extensively investigated. Angiotensinogen is cleaved by renin to generate angiotensin I, which is then converted to angiotensin II (AngII) by the angiotensin-converting enzyme (ACE). AngII, the principal effector peptide of the RAS, induces vasoconstriction and increases sodium and water retention. This leads to an increase in BP. Studies employing mice, in which genes involved in angiotensin generation and encoding AngII receptors have been disrupted, have provided information about the functions of these genes (1-8). However, much less evidence is available on the role that degradation plays in regulating AngII levels. Aminopeptidase A (APA, EC 3.4.11.7) cleaves the N-terminal aspartyl acid residue of AngII to produce AngIII, hence APA has also been called angiotensinase (9). Although the hypotensive effect of purified APA (10) and the hypertensive effects of APA inhibitors in vivo (11) strongly suggest APA involvement in BP regulation, the importance of AngII metabolism in the physiological regulation of BP has not been elucidated. The cDNA cloning of the B lymphocyte differentiation antigen, BP-1/6C3, led to its identification as APA and characterization of the APA gene $(12,13)$. This allowed the generation of BP-1/6C3/APA-deficient mice that could be used to examine the role of APA in immune system, BP homeostasis, and other physiological functions (14,15). Previous studies of the APA-deficient mice have indicated normal fertility, development, and immune system functions (15).

In the current study of BP homeostasis, we used homozygous APA mutant $\left(\mathrm{APA}^{-/-}\right)$, heterozygous APA mutant $\left(\mathrm{APA}^{+/-}\right)$, and wild-type $\left(A P A^{+/+}\right)$mice to examine the role of APA in the regulation of $\mathrm{BP}$ and in the vascular response to increased levels of AngII.

\section{MATERIALS AND METHODS}

\section{Animal preparation}

BP-1/APA knockout mice were derived by breeding heterozygous mice generated by gene targeting and homologous recombination (15). The genetic background of mice used in this study was a mixture of $\mathrm{C} 57 \mathrm{Bl} / 6 \mathrm{~J}$ and $129 \mathrm{~Sv}$ strains. Mice bred and maintained in our animal facility under climate-controlled conditions with a $12 \mathrm{~h}$-light and dark cycle were allowed free access to standard chow (CA-1; Clea Japan Inc, Tokyo, Japan) and drinking water. Experimental protocols approved by the local council on animal care were conducted in adult male mice aged 8 to $60 \mathrm{wk}$. Genomic DNA isolated from tissues was used to verify genotypes by polymerase chain reaction (PCR) as previously described (15). In brief, PCR was performed at $94{ }^{\circ} \mathrm{C}$ for $30 \mathrm{~s}, 56^{\circ} \mathrm{C}$ for $30 \mathrm{~s}$, and $72{ }^{\circ} \mathrm{C}$ for $1 \mathrm{~min}$ for 35 cycles using the following primers. Two

\footnotetext{
'Department of Obstetrics and Gynecology, Nagoya University Graduate School of Medicine, Nagoya, Japan; ${ }^{2}$ Division of Pathology, Clinical Laboratory, Nagoya University Hospital, Nagoya, Japan; ${ }^{3}$ Division of Pathology, Chiba Cancer Center Research Institute, Chiba, Japan; ${ }^{4}$ Division of Developmental and Clinical Immunology, Departments of Medicine, Pediatrics, and Microbiology, University of Alabama at Birmingham and the Howard Hughes Medical Institute, Birmingham, AL 35294.
} 
primers specific for the region deleted in the targeted mutants (P1, 5'-GACAGTGAAGATGAAAGCGG-3' and P2, 5'-ATCAC CACGTACTCCTGCTT-3') amplified a 274-bp product from the wild-type allele only, whereas additional primers specific for the neomycin resistant gene (P3, 5' -GAGGCTATTCGCCTATGACT-3' and P4, 5' -GATATTCGGCAAGCAGGCAT-3') amplified a 538-bp product in the mutated allele only. The wild-type littermates were used as control.

\section{Measurement of Basal BP}

$A P A^{-/-}, A P A^{+/-}$, and $A P A^{+/+}$mice, maintained in a $37^{\circ} \mathrm{C}$ metal chamber, were used for basal BP measurement. Systolic, mean, and diastolic BP was measured by a programmable tail-cuff sphygmomanometer (BP-98A; Softron, Tokyo, Japan). Training measurements were made for $4 \mathrm{~d}$ to acclimatize the animals to the machine, followed by $2 \mathrm{~d}$ of recorded measurements. Two sets of five measurements were taken daily for each mouse and the 1st set discarded. To eliminate bias caused by struggling or other physiological alterations, each set of measurements was accepted only if the standard deviation of the set was $<9 \mathrm{mmHg}$.

\section{Tissue Analysis}

After BP measurement, laparotomy and thoracotomy was performed under anesthesia with intraperitoneal ketamine $(80 \mathrm{mg} / \mathrm{kg})$ and xylazine $(16 \mathrm{mg} / \mathrm{kg})$. The heart and kidneys were then removed and weights recorded. Renal tissue was frozen in liquid nitrogen for analysis of protease activity, and a portion was fixed in $10 \%$ buffered formalin. Fixed samples were embedded in paraffin, sliced at a thickness of $3 \mu \mathrm{m}$ and stained with hematoxylin and eosin for histological examination.

\section{Measurement of APA Activity}

APA activity was measured by a method previously described (16) with slight modification. Crude membrane fractions of renal tissues were obtained by sequential centrifugation and dissolved in $20 \mathrm{mM}$ Tris $\mathrm{HCl}$, pH 7.5 with $0.2 \%$ Triton-X-100 and $25 \mathrm{mM} \mathrm{CaCl}_{2}$. Enzyme activity of the fractions was measured using L-glutamylp-nitroanilide as substrate. APA activity was expressed as the amount of released p-nitroaniline per milligram of protein.

\section{AngII Infusion}

Mice were anesthetized with intraperitoneal ketamine $(80 \mathrm{mg} / \mathrm{kg})$ and xylazine $(16 \mathrm{mg} / \mathrm{kg})$ to allow peritoneal implantation of the osmotic minipumps (model 1003D; Alzet Co, Cupertino, CA, USA). AngII (Sigma Chemical Co, St. Louis, MO, USA) was dissolved in saline at concentrations sufficient to achieve an infusion rate of $750 \mu \mathrm{g} / \mathrm{kg}$ each day. This dosage of AngII was chosen on the basis of pilot studies that indicated the lowest AngII dose for inducing the development of hypertension. Osmotic minipumps containing a saline solution were implanted into the abdominal cavity of control mice. BP was measured from $2 \mathrm{~d}$ before until $6 \mathrm{~d}$ after the implantation of minipumps.

\section{Urine Collection}

For urine collection, all mice were kept with free access to water and food for $24 \mathrm{~h}$ in a metabolic cage that separated urine from feces. Mineral oil was placed in the urine collection chamber to minimize evaporation. After $24 \mathrm{~h}$, urine was collected, spun for $5 \mathrm{~min}$ at $5000 \mathrm{rpm}$ to remove particulate matter and frozen at $-20{ }^{\circ} \mathrm{C}$ until analysis. Body weight and urine excretion were measured every $24 \mathrm{~h}$ for $2 \mathrm{~d}$, and the results were averaged. Urine osmolality, aldosterone, and electrolytes were measured by standard methods (Mitsubishi Kagaku Bio-clinical Laboratories, Inc, Tokyo, Japan).

\section{Statistical Analysis}

Data expressed as mean \pm SEM were analyzed with a 1- or 2-way analysis of variance with a Scheffe's post-hoc test and Student's $t$ test. $P$ values $<0.05$ were considered statistically significant.

\section{RESULTS}

\section{APA Enzymatic Activity}

When APA enzymatic activity was measured in crude membrane preparations from the kidneys of $A P A^{-/-}, A P A^{+/-}$, and $A P A^{+/+}$ mice, the $A P A^{-/-}$mice were found to have only background levels of APA activity as noted in a previous study (15), whereas $\mathrm{APA}^{+/-}$mice had approximately $70 \%$ of the APA activity found in wild-type mice (data not shown).

\section{BP Evaluation in APA Mutant Mice}

To determine the steady-state effects of APA expression levels on $\mathrm{BP}$, we measured the $\mathrm{BP}$ in young $A P A^{-/-}, A P A^{+/-}$, and $A P A^{+/+}$ mice (3-mo-old) by the tail-cuff method. The baseline systolic BP (SBP) was found to be significantly elevated in $\mathrm{APA}^{-/-}$mice $(136.3 \pm 2.4 \mathrm{mmHg}, n=10)(1 \mathrm{mmHg}=133 \mathrm{~Pa})$ compared with $A P A^{+/-}(117.4 \pm 2.0 \mathrm{mmHg}, n=15)$ and $A P A^{+/+}$mice $(114.8 \pm 2.0$ $\mathrm{mmHg}, n=9)(P<0.05)$ (Figure 1A). Mean BP also was significantly higher in $A P A^{-/-}$mice than in the other genotype groups $\left(A P A^{-/-}, 96.4 \pm 2.2 \mathrm{mmHg} ; A P A^{+/-}, 83.6 \pm 1.4 \mathrm{mmHg} ; A P A^{+/+}\right.$, $82.6 \pm 2.1 \mathrm{mmHg} ; P<0.05$ ) (see Figure 1B). Although a trend for higher systolic and mean $\mathrm{BP}$ was noted in $A P A^{+/-}$compared with $A P A^{+/+}$mice, these values did not reach statistical significance.

\section{Size and Histological Evaluation of Kidney and Heart in Young $\mathrm{APA}^{-/-}$Mice}

We also examined the influence of the APA deficiency on growth and development of the kidneys and the heart in young $A P A^{-/-}$ mice (3-mo-old), because several lines of evidence suggest AngII itself as well as hypertension are associated with renal growth and vascular and cardiac hypertrophy $(1,5-8,17-19)$. However, $A P A^{-/-}$ mice grew normally and by appearance they could not be distinguished from $A P A^{+/+}$mice. Kidney, heart, and body weights were not significantly different in the $A P A^{-/-}, A P A^{+/-}$, and $A P A^{+/+}$mice (Table 1). Evaluation of histological sections of kidneys, heart, aorta, adrenal glands, and brain also failed to reveal differences between the $A P A^{-/-}$and $A P A^{+/+}$mice (data not shown).

\section{Urine Excretion Analysis}

Despite the sustained elevation of BP, no morphological changes in kidney were observed. Since compensatory mechanisms such as reduced glomerular flow might protect kidneys, we examined the influence of the APA-deficiency on urine excretion in 3-mo-old 
A

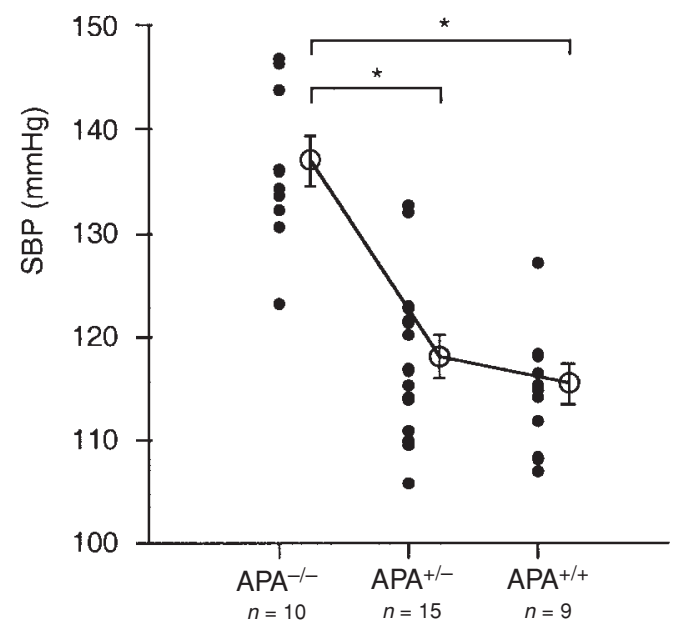

B

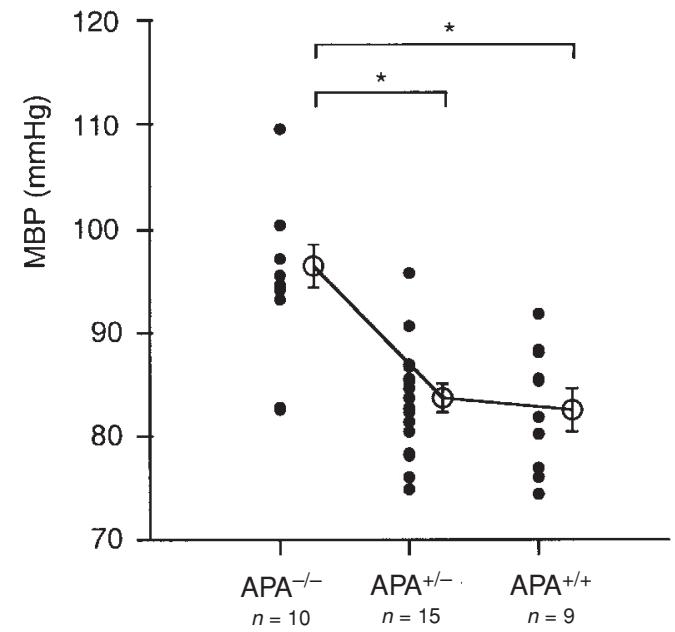

Figure 1. Analysis of the effects of APA deficiency on basal blood pressure level. The systolic (A) and mean (B) blood pressure of $A P A^{-1-}, A P A^{+/-}$, and $\mathrm{APA}^{+/+}$mice at $3 \mathrm{mo}$ ( $n=9$ to 15 per group) were determined by a computed tail-cuff system. Each datum point represents the mean of 2-d measurements taken after a 4 - $d$ training period. The average \pm SEM for each group is represented by an open circle and a bar. ${ }^{*} P<0.05$.

mice. This analysis also was interesting with regard to possible AngII roles in regulating water homeostasis. The data obtained in conscious animals in metabolic cages are given in Table 2. While urine volume and osmolality, and the urinary electrolytes excretion were higher in the $A P A^{-/-}$mice than in the $A P A^{+/+}$mice, the differences were not statistically significant. No difference in urine aldosterone levels was observed between $A P A^{-/-}$and $A P A^{+/+}$mice.

\section{BP Response to AngII Infusion}

The elevation of BP in APA-deficient mice suggested that APA might lower BP through AngII metabolism. To examine the possibility of a direct role for APA in regulating BP during the response to physiological increases in AngII, we monitored the BP response to chronic infusion of AngII in $A P A^{-/-}$and $A P A^{+/+}$mice at 3 mo (Figure 2A). When AngII was infused over a 4-d interval, the SBP increased each day in both groups of mice, but the magnitude of $\mathrm{BP}$ elevation was greater in $\mathrm{APA^{-/ }}$ - mice than in wild-type mice. The increase in SBP on day 2 was $21.2 \pm 2.4 \mathrm{mmHg}$, from $130.6 \pm 1.7$ to $151.8 \pm 2.6 \mathrm{mmHg}$, in $A P A^{-/-}$mice and $9.8 \pm 2.6 \mathrm{mmHg}$, from $119.3 \pm 2.5$ to $129.1 \pm 4.0 \mathrm{mmHg}$, in $A P A^{+/+}$ mice (see Figure 2B). The SBP elevation in response to the AngII administration was significantly greater in the $A P A^{-/-}$mice than in the $A P A^{+/+}$mice. After cessation of the AngII infusion, the SBP dropped over the 1st day and then decreased to preinfusion levels. The SBP remained unchanged in control $\mathrm{APA}^{+/+}$and $\mathrm{APA}^{-/-}$ mice infused with saline.

\section{Effects of Age on BP, Body Weight, and Organ Development in $\mathrm{APA}^{-/-}$Mice}

To examine the age-related changes in BP in APA-deficient mice, we assessed SBP in the $A P A^{-/-}$and $A P A^{+/+}$mice ranging from 8- to $60-$ wk (Figure 3 ). SBP was positively correlated with age similarly in both the $A P A^{-/-}$and $A P A^{+/+}$mice, indicating no additional differences with advancing age between the $A P A^{-/-}$ and $A P A^{+/+}$mice. In addition, we evaluated the development in the early-aging mice at 12 to 15 mo (Table 3 ). $A P A^{-/-}$mice and $A P A^{+/+}$mice were comparable in body, kidney, and heart weight. As observed in the young mice, no histological differences were revealed in the sections of kidneys, heart, aorta, and brain between $A P A^{-/-}$and $A P A^{+/+}$mice (data not shown).

\section{DISCUSSION}

The current study indicates that disruption of the APA gene results in a modest, but sustained BP elevation and hypersensitivity to AngII. The observation that APA deficiency leads to increased BP contrasts with previous reports indicating that mice deficient in renin, angiotensinogen, ACE, and AngII type-1 receptor $\left(\mathrm{AT}_{1}\right)$ have reduced $\mathrm{BP}(1,2,6-8)$. Our study of APA knockout mice is the first to directly demonstrate a role for APA in regulating $\mathrm{BP}$, a function previously suggested by the experiments employing intravenous administration of purified APA (10) and APA inhibitors (11). Our results suggest that other enzymes can metabolize AngII in vitro, including neutral endopeptidase (EC 3.4.24.11; ref 20), prorylendopeptidase (EC 3.4.21.26; ref. 21), and

Table 1. Basal values of body, kidney, and heart weights in 3-mo-old mice

\begin{tabular}{lccccc} 
Group & $n$ & Body weight (g) & $\begin{array}{c}\text { Kidney } \\
\text { weight (mg) }\end{array}$ & $\begin{array}{c}\text { Heart } \\
\text { weight (mg) }\end{array}$ & $\begin{array}{c}\text { Kidney weight (mg)/ Heart weight (mg)/ } \\
\text { body weight (g) } \\
\text { body weight (g) }\end{array}$ \\
\hline APA $^{-/-}$ & 6 & $21.9 \pm 0.4$ & $302 \pm 7$ & $130 \pm 4$ & $13.8 \pm 0.4$ \\
APA $^{+/-}$ & 10 & $22.5 \pm 0.5$ & $294 \pm 10$ & $129 \pm 3$ & $13.1 \pm 0.3$ \\
APA $^{+/+}$ & 7 & $22.8 \pm 0.5$ & $307 \pm 10$ & $133 \pm 4$ & $13.5 \pm 0.3$ \\
\hline
\end{tabular}

Values are mean \pm SEM 
Table 2. Urine excretion data of $A P A^{-/-}$and $A P A^{+/+}$mice

\begin{tabular}{lcc} 
& $\mathrm{APA}^{-/-}$ & $\mathrm{APA}^{+/+}$ \\
& $n=13$ & $n=13$ \\
\hline Body weight $(\mathrm{g})$ & $28.3 \pm 1.1$ & $28.7 \pm 1.0$ \\
Urine volume $(\mu \mathrm{L} / \mathrm{d} / 20 \mathrm{~g})$ & $1119 \pm 129$ & $984 \pm 95$ \\
Urine osmolality $(\mathrm{mOsm} / \mathrm{L})$ & $2789 \pm 177$ & $2450 \pm 87$ \\
Urine aldosterone $(\mathrm{ng} / \mathrm{d})$ & $3.8 \pm 0.4$ & $3.7 \pm 0.2$ \\
$\mathrm{Na}(\mu \mathrm{mol} / \mathrm{d})$ & $356.7 \pm 27.5$ & $287.4 \pm 34.7$ \\
$\mathrm{~K}(\mu \mathrm{mol} / \mathrm{d})$ & $460.9 \pm 46.2$ & $381.4 \pm 48.3$ \\
$\mathrm{Cl}(\mu \mathrm{mol} / \mathrm{d})$ & $481.2 \pm 20.8$ & $371.3 \pm 49.0$
\end{tabular}

the recently described angiotensin converting enzyme 2 (ACE2; ref. 22), do not appear to compensate effectively for the loss of APA. Although the cleavage of phenylalanine from AngII by ACE2 to generate an Ang 1-7 vasodilatator can influence BP and

A

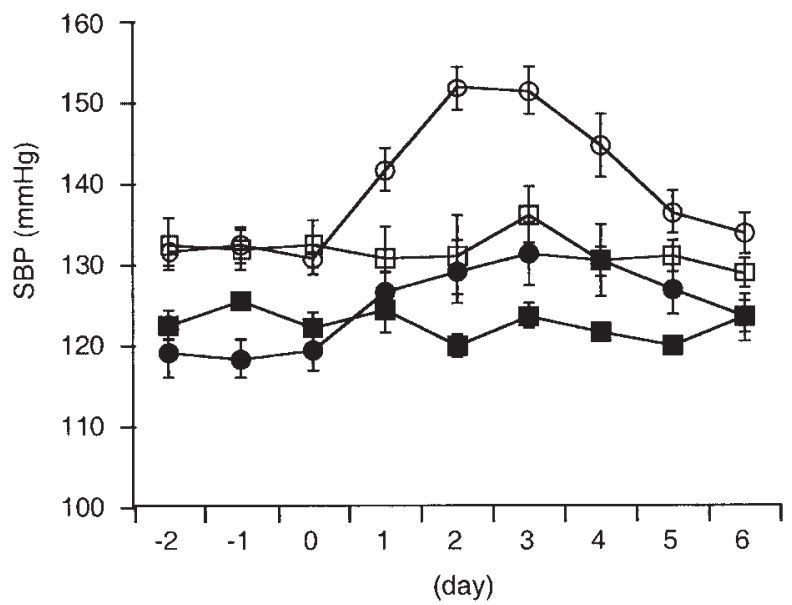

B

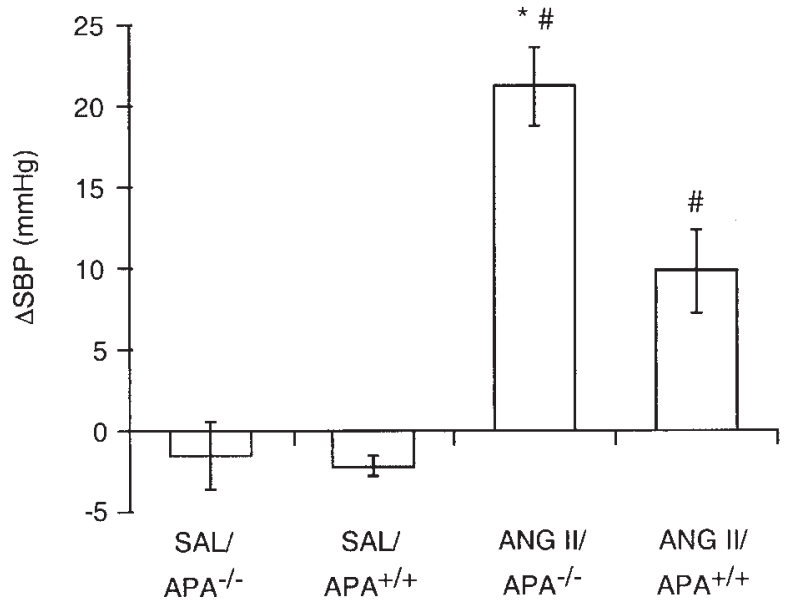

Figure 2. Effects of chronic angiotensin II infusion on systolic blood pressure. A: Daily changes in systolic blood pressure (SBP) in saline infusion $(\mathrm{SAL}) / \mathrm{APA}^{-/-}(\square), \mathrm{SAL}_{\mathrm{APA}}{ }^{+/+}(\mathbf{\square})$, angiotensin II infusion (ANG II)/APA ${ }^{-/-}$ (O) and ANG \| /APA $\left.{ }^{+/+}()^{\prime}\right)$ mice. The implantation of osmotic minipumps was done on day 0 . B: The increase of SBP ( $\triangle S B P$ ) from baseline on day 0 to the levels on day 2 in $\mathrm{APA}^{-/-}$and $A P A^{+/+}$mice. Values are mean $\pm S E M .{ }^{*} P<0.05$ compared with $A P A^{+/+}$mice; $\# P<0.01$ compared with SAL-infused mice.
AngII concentrations $(23,24)$, endogenous ACE2 activity could not reverse the hypertensive effect of APA-deficiency. A compensatory increase in the activity of other APA-like aminopeptidases also is rendered unlikely because the $A P A^{-/-}$mice possess negligible APA-like activity. An important role of APA in metabolizing AngII for BP homeostasis, however, does not exclude additional hormonal or neurological influences of APA deficiency on basal BP. For example, APA hydrolyzes cholecystokinin, which may also modulate the BP (25). It would be interesting to determine whether receptor blockers of AngII and cholecystokinin could efficiently reverse the hypertension in APA-deficient mice.

In addition to the elevated baseline $\mathrm{BP}$, continuous infusion of AngII increased the SBP to a greater extent in $\mathrm{APA}^{-/-}$mice than in $\mathrm{APA}^{+/+}$mice. APA deficiency would increase the relative concentrations of functional AngII by protecting AngII from the degradation. Thus the enhanced response to the AngII infusion in APA-deficient mice is consistent with the biochemical property of APA in metabolizing AngII.

Our findings are more difficult to integrate with previous reports of BP regulation mediated through the RAS within the central nervous system (CNS). The studies employing cerebroventricular infusion of APA inhibitor EC33 (26) or APA (27) suggest that CNS conversion of AngII to AngIII is required to increase BP. Hence, lack of APA in the CNS had been expected to cause hypotension. However, the elevated SBP observed in $A P A^{-/-}$mice that lack APA in all tissues, including the brain, implies that a general APA deficiency can mask or overcome RAS regulatory influences within the brain. Tissue-specific APA knockouts could definitively resolve the question of which RAS compartments are most important for regulating BP.

Remarkably, APA-deficient mice demonstrated no apparent growth and histological alterations in kidney and heart. These findings were unexpected, because there is accumulating evidence that renal and cardiac development may be affected by local RAS. Compensatory mechanisms or refractoriness to AngII are unlikely reasons for the normalcy of these organs because the

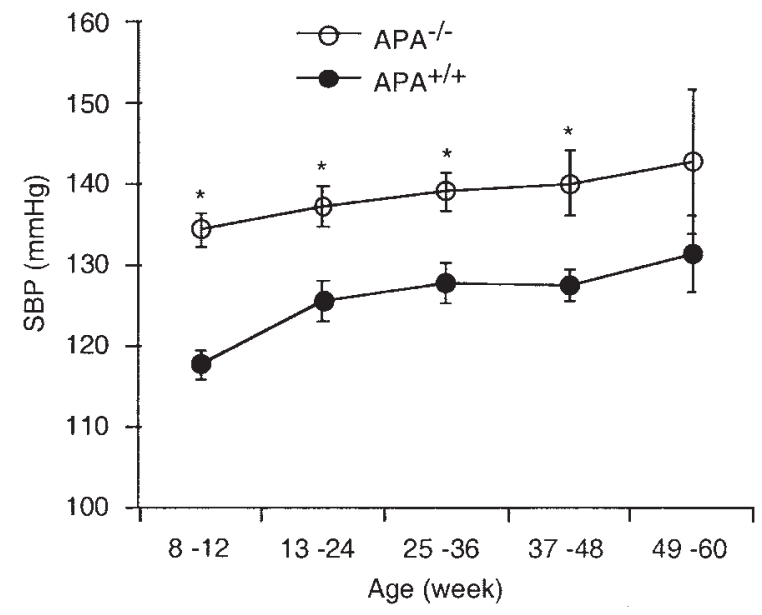

Figure 3. Age-related changes of systolic blood pressure. The systolic blood pressure was measured in $A P A^{-1-}(O)$ and $A P A^{+/+}(0)$ mice ranging from 8- to 60-wk. Values are mean \pm SEM. ${ }^{*} P<0.05$ compared with $\mathrm{APA}^{+/+}$mice. 
Table 3. Basal values of body, kidney, and heart weights in 12- to 14-mo-old mice

\begin{tabular}{lccccc} 
Group & $n$ & Body weight $(\mathrm{g})$ & $\begin{array}{c}\text { Kidney } \\
\text { weight }(\mathrm{mg})\end{array}$ & $\begin{array}{c}\text { Heart } \\
\text { weight (mg) }\end{array}$ & $\begin{array}{c}\text { Kidney weight (mg)/ Heart weight (mg)/ } \\
\text { body weight (g) }\end{array}$ \\
\hline $\mathrm{APA}^{-/-}$ & 5 & $50.2 \pm 1.8$ & $614 \pm 14$ & $294 \pm 41$ & $12.3 \pm 0.6$ \\
$\mathrm{APA}^{+/+}$ & 5 & $49.6 \pm 1.6$ & $602 \pm 20$ & $248 \pm 18$ & $12.2 \pm 0.4$ \\
\hline
\end{tabular}

$A P A^{-/-}$mice have a modest, but significant elevation of their basal BP. Studies of angiotensinogen-, ACE- and $\mathrm{AT}_{1}$-deficient mice indicate that their alterations in kidney and heart development are attributable to a loss of AngII stimulation through the $\mathrm{AT}_{1}$ receptor $(1,5-7)$. APA-deficient mice retain the AngII- $\mathrm{AT}_{1}$ pathway, which could account for the absence of significant heart and kidney damage. Notably, the phenotype of mice lacking AngII type-2 receptor $\left(\mathrm{AT}_{2}\right)$ is quite similar to that of $A P A^{-/-}$mice, in that both types of mutant mice have increased BP, hypersensitivity to AngII, and normal kidney and heart development (4). The absence of cardiac hypertrophy in $\mathrm{AT}_{2}$-deficient mice is interpreted to suggest that hypertensive cardiac hypertrophy may result from growth processes through $\mathrm{AT}_{2}$ (28). Interestingly, increased AngII suppressed $\mathrm{AT}_{2}$ binding more than $\mathrm{AT}_{1}$ binding (29). Although speculative, APA-deficient mice may have reduced $\mathrm{AT}_{2}$ levels, which leads to elevation of $\mathrm{BP}$ without cardiac hypertrophy. Other evidence suggesting that arterial wall hypertrophy requires the sufficiently high-level AngII stimulation to induce transforming growth factor- $\beta(5,30)$ may also account for the absence of cardiac hypertrophy in APA-deficient mice. Hyperstimulation of $\mathrm{AT}_{1}$ by increased AngII in APA-deficient mice might be sufficient to elevate BP, but insufficient to cause renal and cardiac abnormalities via upregulation of transforming growth factor- $\beta$. Experiments are currently in progress to investigate the expression levels of AngII-related genes, including $\mathrm{AT}_{1}$, $\mathrm{AT}_{2}$ and transforming growth factor- $\beta$.

Since renal morphology was not altered in APA-deficient mice, we analyzed urine excretion in the mice. Urine volume and osmolality were not reduced, but rather elevated, thus excluding the possibility that APA-deficient mice decrease their glomerular flow to counter the BP elevation. Although we hypothesized that APAdeficient mice would have an enhanced ability for urine concentration and sodium readsorption, because AngII increases aldosterone levels, we found small, statistically insignificant increases in urine osmolality, urinary potassium excretion, and urinary aldosterone levels in $A P A^{-/-}$mice. These results are in contrast with the finding that urinary electrolytes and aldosterone concentrations are decreased in ACE-deficient mice (31). It is possible that future studies employing water deprivation and sodium restriction will reveal subtle alterations of kidney function in $A P A^{-/-}$mice.

The elevation in basal BP observed in APA-deficient mice suggests that plasma AngII levels are elevated. However, efforts to determine the AngII levels failed, in part because of the requirement for large blood samples and instability of the RIA assay. Accurate determinations of the AngII levels in APAdeficient mice are still needed to confirm that APA deficiency actually leads to an accumulation of circulatory AngII.

In conclusion, APA deficiency increases baseline BP and enhances the hypertensive response to increased levels of AngII.
These findings indicate APA is an essential RAS component in the regulation of BP homeostasis and offer novel insight into the mechanisms for developing hypertension.

\section{ACKNOWLEDGMENTS}

The authors thank Ms M Ohkawa for secretarial assistance. The work was supported in part by Grants-in-Aid from the Ministry of Education, Culture, Sports, Science, and Technology of Japan, and from the Ministry of Public Management, Home Affairs, Posts, and Telecommunications of Japan for specific medical research (in collaboration with Nagoya Teishin Hospital). MDC is an investigator of the Howard Hughes Medical Institute.

Address correspondence and reprint requests to Seiji Nomura, Department of Obstetrics and Gynecology, Nagoya University Graduate School of Medicine, 65 Tsurumai-cho, Showa-ku, Nagoya 466-8550, Japan. Phone: +81-52-744-2261; fax: +81-52-744-2268; e-mail: snomura@med.nagoya-u.ac.jp.

Submitted January 3, 2003; accepted for publication January 10, 2003.

\section{REFERENCES}

1. Krege JH et al. (1995) Male-female differences in fertility and blood pressure in ACE-deficient mice. Nature 375:146-8.

2. Kim H-S et al. (1995) Genetic control of blood pressure and the angiotensinogen locus. Proc. Natl. Acad. Sci. U.S.A. 92:2735-9.

3. Ito $M$ et al. (1995) Regulation of blood pressure by the type 1A angiotensin II receptor gene. Proc. Natl. Acad. Sci. U.S.A. 92:3521-5.

4. Ichiki T et al. (1995) Effects on blood pressure and exploratory behaviour of mice lacking angiotensin II type-2 receptor. Nature 377:748-50.

5. Niimura $F$ et al. (1995) Gene targeting in mice reveals a requirement for angiotensin in the development and maintenance of kidney morphology and growth factor regulation. J. Clin. Invest. 96:2947-54.

6. Oliverio $\mathrm{Ml}$ et al. (1998) Reduced growth, abnormal kidney structure, and type 2 (AT2) angiotensin receptor-mediated blood pressure regulation in mice lacking both ATIA and ATIB receptors for angiotensin II. Proc. Natl. Acad. Sci. U.S.A. 95:15496-501.

7. Tsuchida $S$ et al. (1998) Murine double nullizygotes of the angiotensin type 1A and IB receptor genes duplicate severe abnormal phenotypes of angiotensinogen nullizygotes. J. Clin. Invest. 101:755-60.

8. Yanai K et al. (2000) Renin-dependent cardiovascular functions and renin-independent blood-brain barrier functions revealed by renin-deficient mice. J. Biol. Chem. 275:5-8.

9. Nagatsu I, Gillespie L, Folk JE, Glenner GG. (1965) Serum aminopeptidases, "angiotensinase" and hypertension-I. Degradation of angiotensin II by human serum. Biochem. Pharmacol. 14:721-8.

10. Mizutani S et al. (1987) Effects of human placental aminopeptidases in spontaneously hypertension rats. Med. Sci. Res. 15:1203-4.

11. Ahmad S, Ward PE. (1990) Role of aminopeptidase activity in the regulation of the pressor activity of circulating angiotensins. J. Pharmacol. Exp. Ther. 252:643-50.

12. Wu Q, Lahti JM, Air GM, Burrows PD, Cooper MD. (1990) Molecular cloning of the murine BP-1/6C3 antigen: a member of the zinc-dependent metallopeptidase family. Proc. Natl. Acad. Sci. U.S.A. 87:993-7.

13. Wu Q, Li L, Cooper MD, Pierres M, Gorvel JP. (1991) Aminopeptidase A activity of the murine B-lymphocyte differentiation antigen BP-1/6C3. Proc. Natl. Acad. Sci. U.S.A. 88:676-80.

14. Wang J et al. (1996) The mouse BP-1 gene: structure, chromosomal localization, and regulation of expression by type 1 interferons and interleukin-7. Genomics 33:167-76. 
15. Lin $Q$ et al. (1998) T and B cell development in BP-1/6C3/aminopeptidase Adeficient mice. Immunology 160:4681-7.

16. Glenner GG, McMillan PJ, Folk JE. (1962) A mammalian peptidase specific for the hydrolysis of $\mathrm{N}$-terminal $\alpha$-L-glutamyl and aspartyl residues. Nature 194:867.

17. Sadoshima J, XU Y, Slayter H, Izumo S. (1993) Autocrine release of angiotensin II mediates stretch-induced hypertrophy of cardiac myocytes in vitro. Cell 75:977-84.

18. Oliverio $\mathrm{Ml}$ et al. (1998) Renal growth and development in mice lacking $\mathrm{AT}_{1} \mathrm{~A}$ receptors for angiotensin II. Am. J. Physiol. 274:F43-50.

19. Ichihara $S$ et al. (2001) Angiotensin II type 2 receptor is essential for left ventricular hypertrophy and cardiac fibrosis in chronic angiotensin II-induced hypertension. Circulation 104:346-51.

20. Walter R, Simmons WH, Yoshimoto T. (1980) Proline specific endo- and exopeptidases. Mol. Cell. Biochem. 30:111-27.

21. Gafford JT, Skidgel RA, Erdos EG, Hersh LB. (1983) Human kidney "enkephalinase," a neutral metalloendopeptidase that cleaves active peptides. Biochemistry 22:3265-71.

22. Tipnis SR et al. (2000) A human homolog of angiotensin-converting enzyme. Cloning and functional expression as a captopril-insensitive carboxypeptidase. J. Biol. Chem. 275:33238-43.
23. Turner AJ, Hooper NM. (2002) The angiotensin-converting enzyme gene family: genomics and pharmacology. Trends Pharmacol. Sci. 23:177-83.

24. Crackower MA et al. (2002) Angiotensin-converting enzyme 2 is an essentia regulator of heart function. Nature 417:822-8.

25. Migaud $M$ et al. (1996) The in vivo metabolism of cholecystokinin (CCK-8) is essentially ensured by aminopeptidase A. Peptides 17:601-7.

26. Reaux A et al. (1996) Aminopeptidase A inhibitors as potential central antihy pertensive agents. Proc. Natl. Acad. Sci. U.S.A. 96:13415-20.

27. Wright JW, Mizutani S, Murray CE, Amir HZ, Harding JW. (1990) Aminopeptidaseinduced elevations and reductions in blood pressure in the spontaneously hypertensive rat. J. Hypertension 8:969-74.

28. Iyer SN, Chappell MC, Brosnihan KB, Ferrario, CM. (1999) Role of AT and AT receptors in the clearance of angiotensin II. J. Cardiovasc. Pharmacol. 31:464-9.

29. Ouali R, Berthelon MC, Begeot M, Saez JM. (1997) Angiotensin II receptor subtypes $\mathrm{AT}_{1}$ and $\mathrm{AT}_{2}$ are down-regulated by angiotensin II through $\mathrm{AT}_{1}$ receptor by different mechanisms. Endocrinology 138:725-33.

30. Schultz JEJ et al. (2002) TGF-(1 mediates the hypertrophic cardiomyocyte growth induced by angiotensin II. J. Clin. Invest. 109:787-96.

31. Esther CRJ et al. (1996) Mice lacking angiotensin-converting enzyme have low blood pressure, renal pathology, and reduced male fertility. Lab. Invest. 74:953-65 